\title{
The signature of phylogenetic constraints on food-web structure
}

\author{
Louis-Félix Bersier*, Patrik Kehrli ${ }^{1}$ \\ Department of Biology, Unit of Ecology \& Evolution, University of Fribourg, ch. du Musée 10, CH-1700 Fribourg, Switzerland
}

\begin{abstract}
A B S T R A C T
Understanding the processes underlying food-web structure and organization remains one of the major tasks of ecology. While first attempts were mostly based on niche theory, with body size of species imposing a hierarchical structure for consumer species, it has been recently suggested that phylogenetic constraints may be more fundamental to understand who eats whom in natural communities. Models of food-web structure built on basic evolutionary assumptions are able to adequately reproduce the topology of real food-webs. Here, we analyze different implications of phylogenetic constraints on trophic structure, and present preliminary results. Our exploration of the relationship between trophic and taxonomic similarity in food-webs shows that phylogeny and trophic structure are closely linked. Interestingly, the relationship is stronger for trophic similarity between prey (similarity measured by shared predators species, or predatory similarity) than between consumer species (similarity measured by shared prey species, or dietary similarity). When relating body mass of prey and predators, slopes of major axis regressions within taxonomic groups differ markedly from the global pattern; similar differences between taxonomic levels appear when exploring the relationship between body mass of predators and the range in body mass of their prey, and vice versa. These results are important to understand how evolutionary processes shaping body sizes can affect food-web structure.
\end{abstract}

\section{Introduction}

A large effort has been devoted to the study of food-web structure, a research theme pioneered by Cohen in the seventies (Cohen, 1977, 1978; Pimm, 1982). This undertaking is of high interest not only for fundamental but also practical reasons, the latter becoming paramount in face of global changes (e.g., Wrona et al., 2006). Together with first generalizations on food-web structure, stochastic models attempting to explain the observed patterns were proposed (Cohen, 1978; Sugihara, 1982). The most celebrated is certainly the cascade model (Cohen and Newman, 1985), which postulates a simple hierarchy among consumers, with a species of a given rank being allowed to consume any species of lower rank. Since consumers are generally larger than their prey, this hierarchy was hypothesized to reflect body size (Warren and Lawton, 1987; Lawton and Warren, 1988). With only two parameters, species richness $S$ and connectance $C$ (the observed number of links $L$ divided by the total number of possible links $S^{2}$ ), this model was able to adequately represent some structural properties of the first described food-webs (Cohen et al., 1990). However the quality of these early data was rightly criticized (Paine, 1988), and more recent and highly resolved food-webs possess characteristics that are not accounted for by the

\footnotetext{
* Corresponding author. Tel.: +41263008869.

E-mail address: louis-felix.bersier@unifr.ch (L.-F. Bersier).

${ }^{1}$ Present address: Station de recherche Agroscope Changins-Wädenswil, CP 1012, CH-1260 Nyon, Switzerland.
} 
cascade model (Neubert et al., 2000; Williams and Martinez, 2000). Notably, the cascade model produces much too many chordless cycles in niche overlap graphs (Cohen and Palka, 1990; Huxham et al., 1996). Such graphs played an important role in the development of food-web models (Sugihara, 1984). They are derived directly from food-webs by joining each species - vertices - that share at least a prey by an undirected edge. As such, they portray the exploitative competition structure of the community. An absence of chordless cycle (i.e., a subgraph with four or more vertices forming a cycle without any shortcutting edge between them) in a niche overlap graph indicates a very cohesive trophic structure, with the possibility to order all consumers along a single niche dimension (e.g., resource body size). Chordless cycles were found to be virtually absent in early described food-webs (Sugihara, 1982), but it has been shown that they are frequent in many recent and highly resolved food-webs (e.g., Huxham et al., 1996).

These weaknesses of the cascade model fostered Williams and Martinez (2000) to propose the so-called niche model, which represents a radical improvement in fitting power. In this model, a hierarchy among species is also postulated, but consumers are constrained to prey upon a continuous range of resource species. This model is very powerful at describing many structural properties of high-quality data (Martinez and Cushing, 2006). However, the continuity constraint produces only food-webs without chordless cycles. More importantly, diets of consumers have been found not to be continuous (Cattin et al., 2004), which invalidates the core hypothesis of the niche model (Bersier et al., 2006).

Interestingly, the development of the cascade and the niche model was based mostly on ecological arguments, namely niche theory. Though Williams and Martinez (2000) suggested that evolutionary processes may underlay the patterns generated by the niche model, the simple set of rules of this model does not explicitly involve an evolutionary approach. It is sensible that phylogenetic constraints may play an important role in determining who eats whom in a community. Because taxonomically similar species share similar ancestors, they tend to be adapted to similar types of resource. Examples abound in the literature: all species of the Trochiliformes order (hummingbirds) have a beak specialized for nectar feeding, a diet complemented with small arthropods; all species of the Hemiptera order possess styletlike mouth parts admirably suited for sucking out liquids from plants and sometimes from animals. Recent events of adaptive radiation (Schluter, 2000) are cases where the link between phylogeny and trophic structure can vanish. However, even in classical cases of radiation like the Hawaiian honeycreepers (Drepanidinae), one can recognize three tribes within which species harbour very similar beaks (Pratt, 2005).

Despite this straightforward line of arguments, few attempts have linked phylogeny and trophic structure (e.g., Cousins, 1985), and evolutionary thinking has only recently pervaded in food-web ecology. Cattin et al. (2004) suggested the nested-hierarchy model, which explicitly takes evolutionary processes into account. The major difference with former models is that the process of generating food-webs is sequential: consumers are added one by one in the community, and their diet depends on existing ones. This feature is meant to represent an evolutionary process where a new consumer species can "inherit" prey species of a group (phylogenetic constraint), or can eat yet unexploited prey species (adaptation). This model performs as well as the niche model with regard to classical food-web properties (e.g. the proportion of top, intermediate, and basal species), but outperforms it by correctly accounting for the level of chordless cycles found in real communities (Bersier et al., 2006). Community ecologists are becoming more and more aware of the importance of historical effects, and notably on "deep history", on community structure (e.g., Drake, 1990; Losos, 1996; Price, 2003; Vitt and Pianka, 2005), and food-web models witness this development. Population models based on evolutionary dynamics (e.g., Caldarelli et al., 1998; Drossel et al., 2001; Yoshida, 2002, 2003; Loeuille and Loreau, 2005) as well as topological models (Cattin et al., 2004; Melián, 2005; Rossberg et al., 2005, 2006a; Rossberg, 2007) are now well established.

We are at an early phase of the development of a global theory linking evolutionary processes and food-web structure, and many questions are still open. A key issue is the search for selection processes acting globally within clades, and the understanding of their effect at the community level. Notably, for intermediate species that are consumer as well as prey, the question raises if selective pressures interact in a way that yields predictable trophic structures? Here, an important trait is certainly body size, which is known to be related to metabolic and demographic parameters (e.g., Brose et al., 2006a), and has been suggested to be implied in speciation events in fishes (e.g., Nagel and Schluter, 1998) and reptiles (Richmond and Jockusch, 2007). From the point of view of a single species, larger individuals may benefit from lower predation rate, but at the same time they may become less efficient in their role of predator, a feature found in several studies (e.g., Persson, 1987; Tripet and Perrin, 1994; Wahlstrom et al., 2000; Aljetlawi et al., 2004; Finstad et al., 2006). The possibility to respond to these divergent pressures is obviously limited by physiological constraints dictated by taxonomy. The knowledge of how selection and adaptation influences body sizes within taxonomic groups at different levels is the first step toward the formulation of a theory involving ecological and evolutionary processes.

In this paper, we explore how phylogeny is linked to foodweb structure. We first use a global approach where we compare directly phylogenetic and trophic structures. Phylogenetic and trophic structures are described by similarity matrices, where pairwise resemblance between species is measured based on the distance to a common ancestor, and on their shared prey and/or predators, respectively. Second, we investigate how phylogeny can affect the relationship between consumer and resource body masses. In a recent paper, Brose et al. (2006b) used a large data set and showed that the consumer body mass scales with resource body mass following a power law with an exponent significantly larger than one. This indicates that the gap between consumers' and resources' masses increases with body size. Here, we reanalyze the data set to test if this relationship also holds for individual taxonomic groups. Additionally, we analyze the range of resources' body masses as a function of consumer body mass, and conversely the range of consumers' body 
masses as a function of resource body mass, and explore if the observed trends hold in different taxonomic groups.

\section{Material and methods}

\subsection{Data set}

Trophic and taxonomic similarity is computed for five foodwebs, Chesapeake Bay (Baird and Ulanowicz, 1989), Coachella Valley (Polis, 1991), Skipwith Pond (Warren, 1989), St-Martin Island (Goldwasser and Roughgarden, 1993), and Ythan estuary (Hall and Raffaelli, 1991). They are chosen because the determination of trophic links was based on direct observations and not on expert knowledge or published information (e.g., Martinez, 1991; Havens, 1992; Deb, 1997). In the latter case, it is likely that taxonomic information is used to infer trophic interactions, which invalidates the test.

For the analysis of body masses, we use the large data set of Brose et al. (2005), which encompasses 16,863 records of trophic interactions from 10 food-web studies (Warren, 1989; Dawah et al., 1995; Yodzis, 1998; Memmott et al., 2000; Cattin Blandenier, 2004; Woodward et al., 2005; Jonsson et al., 2005; Harper-Smith et al., 2005; Ledger, Edwards, and Woodward, unpublished data; Jacob, Brey, and Mintenbeck, unpublished data), supplemented by data for some specific groups (Andrassy, 1956; Hansen et al., 1994; Ulrich, 1999, 2001; Scharf et al., 2000; Pinnegar et al., 2003; Cohen et al., 2005; Dell, unpublished data; Rayner, unpublished data; Ruess, unpublished data; Warren, unpublished data). For the purpose of comparison and to avoid pseudoreplication, we retain the 5103 records of Brose et al. (2006b). We extended the complete data set with taxonomic information. The 1658 taxa of the full data set were classified according to the following 18 levels: species, genus, tribe, subfamily, family, superfamily, infraorder, suborder, order, superorder, infraclass, subclass, class, superclass, subphylum, phylum, subkingdom, and kingdom. This information was retrieved between March and June 2006 from the Integrated Taxonomic Information System (ITIS) (www.itis.gov).

\subsection{Analyses}

Trophic similarity is measured from the binary food-web matrices $\left(\mathrm{a}=\left[a_{i j}\right], a_{i j}=1\right.$ if taxon $j$ preys on taxon $i$, and $a_{i j}=0$ otherwise) with the use of Jaccard index of similarity (Legendre and Legendre, 1998; Williams and Martinez, 2000). This index is the number of prey and/or of consumers shared by $i$ and $j$ divided by the pair's total number of prey and/or of consumers. We measure trophic similarity in three ways, firstly by using for each taxon the total information on prey and predators (each taxon $i$ is described by its set of resource a' and its set of consumers a; trophic similarity-comparison between all species), secondly by considering only the set of prey a' (dietary similarity-comparison between consumer species), and thirdly by taking only consumers a into account (predatory similarity-comparison between prey species).

To measure taxonomic similarity, we first assign to each taxon its taxonomic membership by using the following 10 levels: (1) kingdom, (2) superphylum, (3) phylum, (4) sub- phylum, (5) class, (6) subclass/superorder, (7) order, (8) suborder/superfamily, (9) family, (10) genus. Taxonomic similarity between $i$ and $j$ is measured as the value of the most precise common taxonomic level (for example, 10 for two species of the same genus) divided by one plus the value of the most detailed level of any of both taxa (Cattin et al., 2004). This measure of similarity is used as a surrogate for the time of phylogenetic divergence between two taxa. We perform a Mantel test (Legendre and Legendre, 1998) to compare the matrices of trophic and taxonomic similarity. We use Pearson's correlation coefficient as the test statistic, and evaluate its significance with 2000 permutations. The standard errors of the correlations coefficients are estimated with a bootstrap procedure, with whole matching rows and columns of both similarity matrices as resampling units. For each food-web, the coefficients for taxonomic-dietary similarities and taxonomic-predatory similarities were compared with Welch's approximate t test (Sokal and Rohlf, 1995).

The relationship between consumer and resource body masses is evaluated with major axis regression (Sokal and Rohlf, 1995), which minimizes the squared residuals perpendicularly to the regression line, on the $\log _{10}$ of body masses [ $g$ ]. Major axis regression is performed for the complete data set (5093 trophic interactions in 844 taxa) and for two subgroups, the phyla Arthropoda (2394 trophic interactions in 201 taxa) and chordates (2197 trophic interactions in 538 taxa). We do not present here any analyses of finer taxonomic resolution. There are two possibilities to define these subgroups, either by considering taxa in their role of consumer or of resource, and we show here only the results where groups are formed with respect to predators. We estimate the standard error of the slope and intercept parameters by the use of a bootstrap procedure. However, because in our data set each consumer taxon is typically involved in more than one trophic interaction, we do not resample individual trophic interactions but complete sets of links of consumers (observational units are not trophic links but consumer taxa).

We also analyze how the ranges of body masses of resources (for consumer taxa) and of consumers (for resource taxa) vary with the body mass of taxa. The range can be measured as the difference [ $g$ ] between the largest and smallest resource, or consumer, of the considered taxon, divided by its own body mass. Without standardization for taxon's body mass, one would trivially expect a positive relationship. Simple linear regressions are performed among various taxonomic levels. Only species that have at least two prey and two predators (generalist intermediate species) are considered in the analysis.

\section{Results}

The results of the Mantel tests comparing taxonomic and trophic similarity yield significant results for the five foodwebs considered (Table 1). This confirms the close link between phylogeny and food-web structure. Moreover, predatory similarity is in general more tightly related to the phylogenetic structure than dietary similarity, with statistically significant differences for three food-webs. This indicates that the taxonomic structure of the community may be 
Table 1 - Similarity between taxonomic and trophic structure in five food-webs

\begin{tabular}{|c|c|c|c|c|c|c|}
\hline & \multicolumn{2}{|c|}{ Trophic similarity } & \multicolumn{2}{|c|}{ Dietary similarity } & \multicolumn{2}{|c|}{ Predatory similarity } \\
\hline & R (S.E.) & $P$ & $r$ (S.E.) & $P$ & $r$ (S.E.) & $P$ \\
\hline Chesapeake Bay & $0.427(0.045)$ & $<0.001$ & $0.231(0.057)$ & $<0.001$ & $0.330(0.092)$ & 0.002 \\
\hline Coachella* & $0.618(0.036)$ & $<0.001$ & $0.159(0.057)$ & 0.040 & $0.635(0.036)$ & $<0.001$ \\
\hline Skipwith Pond* & $0.431(0.033)$ & $<0.001$ & $0.101(0.050)$ & 0.077 & $0.459(0.046)$ & $<0.001$ \\
\hline St-Martin Island & $0.605(0.047)$ & $<0.001$ & $0.270(0.067)$ & $<0.001$ & $0.131(0.073)$ & 0.051 \\
\hline Ythan estuary* & $0.304(0.033)$ & $<0.001$ & $0.099(0.027)$ & $<0.001$ & $0.206(0.035)$ & $<0.001$ \\
\hline
\end{tabular}

Trophic similarity is measured in three ways: considering all shared resources and consumers (trophic similarity), only shared resources (dietary similarity), and only shared consumers (predatory similarity).

$r$ (S.E.) is Pearson's product moment correlation with its standard error; P is obtained by a Mantel test $\left(H_{0}: r=0\right)$; a food-web with a star (*) indicates that the correlation coefficients for dietary-taxonomic similarity and predatory-taxonomic similarity are significantly different at the $5 \%$ level.

more closely related to the trophic organization of prey than of predators.

The analysis of the relationship between consumer and resource body sizes yields an interesting result: when considered within arthropod and chordate consumers, the relationship is reversed compared to the global pattern (Fig. 1). With $a$ the intercept, $b$ the slope, $R^{2}$ the coefficient of determination, and $P$ the probability that the slope is different from 1 , the test for the complete data set yields: $a=1.801$, $b=1.160, R^{2}=0.86, P=<0.001$; for the arthropod predators: $a=-0.793, b=0.529, R^{2}=0.85, P=<0.001$; and for the chordate predators: $a=2.687, b=0.556, R^{2}=848, P=<0.001$. Thus, both taxonomic entities have slopes very similar $(b \approx 0.5)$ and significantly smaller than one, indicating that prey become disproportionately larger for larger predators. One reaches the opposite conclusion when all species are pooled.

When examining how the range of relative prey body mass scales with body mass of predators (Table 2), we observe that the slope is always positive, indicating that larger predators can prey upon a larger range of prey. This relationship is

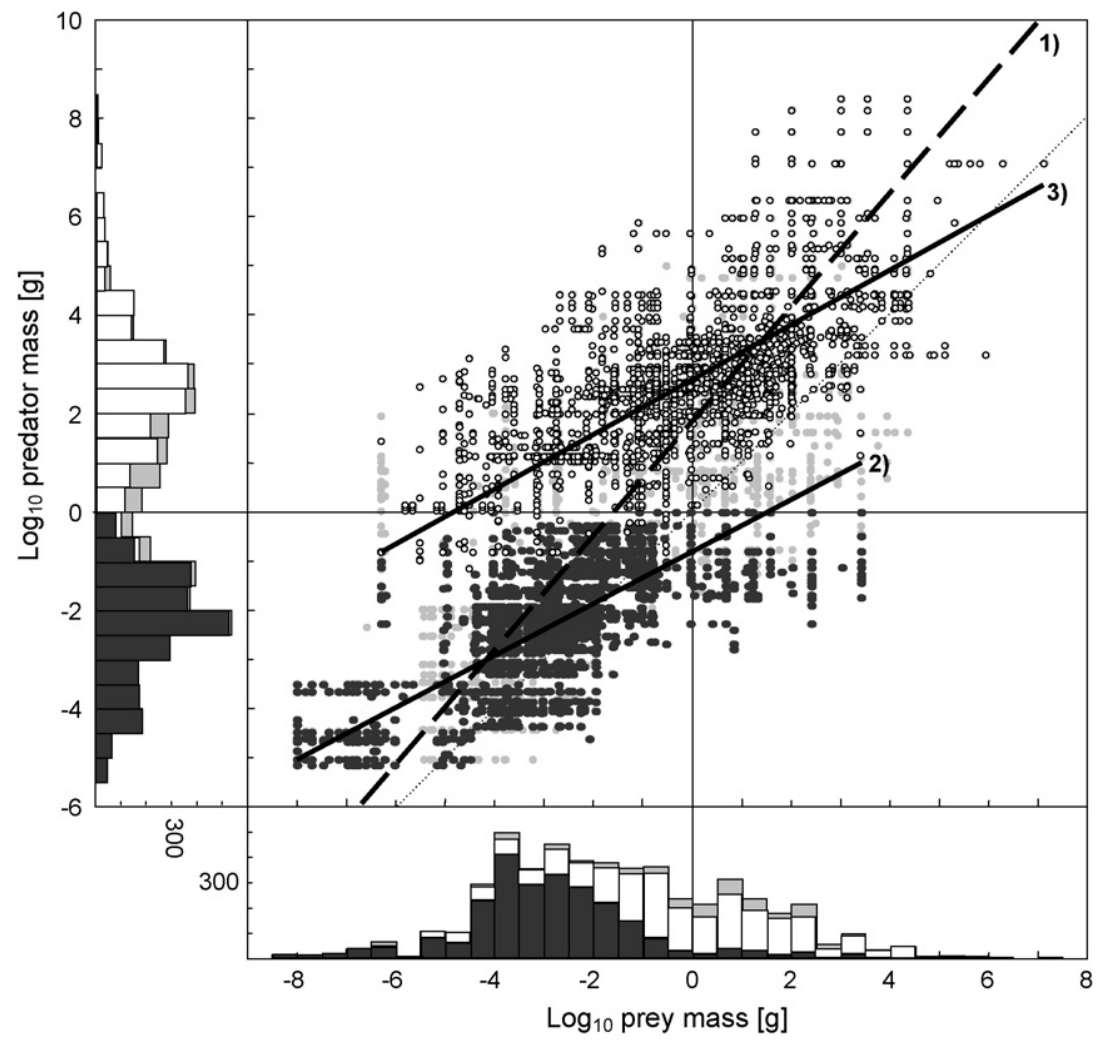

Fig. 1 - Predator body mass versus prey body mass for (1) all trophic interactions, (2) for interactions of arthropod consumers (dark grey dots), and (3) of chordate consumers (white dots). Major axis regression for (1) is given by the dashed line, and by solid lines for (2 and 3).

Statistics are given in the text. The thin dotted line indicates where predators and prey have identical body mass. The left and bottom inserts give the frequency distribution of data points for consumers and prey, respectively; dark grey and white bars correspond to interactions of arthropod and chordate consumers, respectively. Light grey dots and bars refer to species not belonging to arthropods nor to chordates. 
Table 2 - Linear regression analyses of the range of relative body mass of prey against consumer body mass, and of the range of relative body mass of consumers against prey body mass

\begin{tabular}{|c|c|c|c|c|c|c|c|c|c|c|}
\hline \multirow[t]{3}{*}{ Phylum } & \multirow[t]{3}{*}{ Subphylum } & \multirow{3}{*}{ Class } & \multirow[b]{3}{*}{ Order } & \multirow[b]{3}{*}{ d.f. } & & \multicolumn{3}{|c|}{$\begin{array}{l}\text { Taxon as a resource } \\
Y=\text { range of relative } \\
\text { consumer mass }\end{array}$} \\
\hline & & & & & \multicolumn{3}{|c|}{$\begin{array}{l}\text { Taxon as a consumer } \\
\mathrm{Y}=\text { range of relative } \\
\text { prey mass } \\
\mathrm{X}=\text { mass of consumer }\end{array}$} & \multicolumn{3}{|c|}{$X=$ mass of resource } \\
\hline & & & & & $R^{2}$ & Slope & $P$ & $R^{2}$ & Slope & $P$ \\
\hline Rotifera & & & & 12 & 0.986 & 1.05 & $<0.001$ & 0.931 & -0.91 & $<0.001$ \\
\hline Arthropoda & & & & 127 & 0.015 & 0.20 & 0.169 & $<0.001$ & 0.002 & 0.99 \\
\hline & & & Araneae & 47 & 0.748 & 0.64 & $<0.001$ & 0.136 & 0.77 & 0.011 \\
\hline & Crustacea & & & 10 & 0.122 & 0.80 & 0.323 & 0.004 & 0.23 & 0.859 \\
\hline & & Insecta & & 69 & 0.246 & 0.92 & $<0.001$ & 0.038 & 0.27 & 0.109 \\
\hline & & & Odonata & 10 & 0.661 & 0.85 & 0.004 & 0.152 & 0.89 & 0.265 \\
\hline & & & Coleoptera & 33 & 0.452 & 0.52 & $<0.001$ & 0.064 & 0.37 & 0.157 \\
\hline & & & Diptera & 12 & 0.004 & 0.11 & 0.837 & 0.003 & 0.08 & 0.868 \\
\hline Chordata & & & & 22 & 0.0004 & 0.03 & 0.931 & 0.030 & -0.20 & 0.444 \\
\hline All taxa & & & & 164 & 0.058 & 0.21 & 0.002 & 0.069 & -0.18 & $<0.001$ \\
\hline
\end{tabular}

The range of relative body mass of prey is the difference $[g]$ between the largest and the smallest prey, divided by the body mass of the consumer. This analysis includes only intermediate species that prey on more than one species; d.f. is the degrees of freedom, $R^{2}$ the coefficient of determination $\left(H_{0}\right.$ : slope $\left.=0\right)$.

particularly strong for Araneae, Insecta, and Coleoptera; in contrast, the range for chordate predators appears to remain constant. Concerning the range of body mass of predators, the general trend is reversed: the slope is negative for all species pooled. It indicates that larger prey species tend to be preyed upon by species being in a smaller range of body masses. It is very interesting to note that, when considering finer taxonomic levels, this negative relationship holds for rotifers and chordates, but not for arthropods. Thus, larger arthropods have a larger range of predators. In summary, phylogeny interferes with the global pattern both for prey and predators.

\section{Discussion}

Our results confirm the role of phylogenic constraints in the structure of trophic interactions. Mantel tests always reveal a highly significant relationship between species similarity measured with information on trophic links and on taxonomic status (Cattin et al., 2004). Our findings further highlight an intriguing pattern: the trophic structure of prey appears to be more related to phylogeny than that of predators, a result that should be confirmed with other data. The ecological role of a species can be understood as the outcome of a balance between phylogenetic constraints, which bounds taxonomically similar species to behave similarly, and a series of adaptations, the adaptive syndrome, which allows species to diverge in their ecology (Price, 2003). If phylogenetic constraints were the only determinant of trophic interactions, we would expect a perfect match between taxonomy and trophic structure; the Mantel test would yield a coefficient close to one. As soon as adaptation comes into play, the match between taxonomy and trophic structure diminishes, and Mantel's coefficient becomes smaller than one. In this framework, our results indicate firstly that taxonomically related prey species tend to be preyed upon by similar consumers (higher phylogenetic constraint), and that this relationship is weaker when considering taxonomically related consumer species and their resources. In other words, a clade tend to be more generalist with regard to its prey, and more specialized with regard to its predators. Secondly, it shows that adaptations to avoid predators play a smaller role than adaptations to secure resources in structuring trophic interactions. A possible explanation for this asymmetric relationship may be that, to survive, individuals may have no other choice than to adopt an opportunistic feeding behaviour, which decreases the relationship between phylogeny and trophic structure for species in their role of consumers.

In this respect, it is also intriguing to note that such an asymmetric relationship is predicted by a recent model - the matching model - where phylogenetic evolution is explicitly accounted for (Rossberg et al., 2006b). It is possible to measure phylogenetic similarity between species for these models, which is not the case with others like the nested-hierarchy model. In their model, Rossberg et al. (2006b) establish trophic links between species by matching abstract "foraging traits" of consumers and "vulnerability traits" of prey. The traits evolve neutrally. Fitting the model to data suggests that vulnerability traits generally evolve slower than foraging traits. As a result, phylogenetic and trophic structures are more closely linked for prey in the model, in agreement with our observations. These considerations are important not only because they represent patterns that should be correctly accounted for by models, but also for our understanding of evolutionary processes underlying global trophic structure.

Together with phylogeny, body size is one of the major component explaining the architecture of food-webs (e.g., Lawton and Warren, 1988; Cohen et al., 1993, 2003; Brose et al., 2006a). Brose et al. (2006b) analyzed the relationship between the body mass of consumer and of resource and found that larger predators tend to become disproportionately larger than their prey. This trend is however reversed when considering trophic interactions within chordate and arthropod consumers (Fig. 1), and other differences are apparent when considering finer taxonomic groups (data not shown here). The evolutionary reasons and ecological consequences of this trend's reversal still remain to be elucidated. It is certainly not 
a trivial task since the strategy of a given species will affect the strategy of the other interacting species-a game theoretical situation in a complex food-web framework (Weitz and Levin, 2006). One partial explanation is linked to basic differences in body plans (exo-versus endoskeleton), which limits the range of achievable body sizes in each group. However, the fact that the slopes for chordates and arthropods are smaller than one and are very similar still awaits to be elucidated. Because body size is a major factor affecting growth, reproduction, space use, and abundance of organisms (Damuth, 1981; Brose et al., 2006a), understanding how phylogeny interacts with this key feature is a necessary step toward a global theory of community structure (Siemann et al., 1996).

We note that other trend reversals in taxonomic sub-units have already been documented. Notably the general negative relationship between body mass and abundance does not hold within many bird tribes, where larger species tend to be more abundant (Nee et al., 1991). A possible explanation is the following: metabolic constraints underlying the negative trend act globally, and are best detected with data sets encompassing species spanning a broad range of body sizes. When focussing on tightly related groups, speciation events may proceed from large and generalist ancestral species toward more specialized and smaller sister species. The share of resource for these more recent species may on average become smaller and smaller, and this will negatively affects their abundance (Sugihara et al., 1993).

When considering, for a consumer, the range of relative (i.e., standardized by body mass of the focal species) body masses of its prey, and for a resource the range of relative body masses of its predators, it is again apparent that the relationships can strongly vary between taxonomic entities. The global pattern reveals that larger consumers tend to prey on a larger palette of prey in term of body masses; at the same time, larger resources tend to be consumed by predators in a narrower range of body masses. This global pattern is easily understood: for larger consumers, the range of possible preyin term of body mass - becomes wider; similarly, for larger prey this range becomes smaller. However, it is interesting to note clear differences between taxa. This trend is very strong for consumer spiders and insects: larger species can prey upon a much larger range of prey masses than smaller ones. In contrast, for chordate consumers the positive trend vanishes, indicating a constant range of prey masses (Table 2). The effect of taxonomy is even more striking with prey, with a positive relationship for all arthropod taxa while the global trend is negative. For these taxa, larger preys suffer from a larger range of predators. The regression is however significant only for spiders. It must be noted however that the sample size is generally modest, and these relationships should be confirmed with more data.

Phylogeny and body size interact in various ways in the structure of food-webs. Elucidating their specific and joint impacts on trophic organization will provide a much sharper image of community organization (Price, 2003; Cattin et al., 2004; Loeuille and Loreau, 2005). We have presented here different ways to look at this problem, and offered preliminary results. Other researches are needed before being able to formulate an articulate theory. A fruitful research agenda is certainly to combine modelling and empirical works on this topic (e.g., Rossberg et al., 2005), a joint venture that should ultimately help to better assess the impacts of global change on community functioning.

\section{Acknowledgements}

We are grateful to all researchers involved in the data collection of the analyses presented here, and to A. Rossberg for his help and inputs. This research is funded by the Swiss National Science Foundation (grant 3100A0-113843).

\section{R E F E R E N C E S}

Aljetlawi, A.A., Sparrevik, E., Leonardsson, K., 2004. Preypredator size-dependent functional response: derivation and rescaling to the real world. J. Anim. Ecol. 73, 239-252.

Andrassy, I., 1956. Die Rauminhalts- und Gewichtsbestimmung der Fadenwürmer (Nematoden). Acta Zoologica 2, 11-15.

Baird, D., Ulanowicz, R.E., 1989. The seasonal dynamics of the Chesapeake Bay ecosystem. Ecol. Monogr. 59, 329-364.

Bersier, L.-F., Cattin, M.-F., Banašek-Richter, C., Baltensperger, R., Gabriel, J.-P., 2006. Reply to Martinez and Cushing. In: Pascual, M., Dunne, J.A. (Eds.), Ecological Networks: Linking Structure and Dynamics. Oxford University Press, pp. 91-92.

Brose, U., Cushing, L., Berlow, E.L., Jonsson, T., Banasek-Richter, C., Bersier, L.F., Blanchard, J.L., Brey, T., Carpenter, S.R., Cattin Blandenier, M.F., Cohen, J.E., Dawah, H.A., Dell, T., Edwards, F., Harper-Smith, S., Jacob, U., Knapp, R.A., Ledger, M.E., Memmott, J., Mintenbeck, K., Pinnegar, J.K., Rall, B.C., Rayner, T., Ruess, L., Ulrich, W., Warren, P., Williams, R.J., Woodward, G., Yodzis, P., Martinez, N.D., 2005. Body sizes of consumers and their resources. Ecology 86, 2545.

Brose, U., Williams, R.J., Martinez, N.D., 2006a. Allometric scaling enhances stability in complex food webs. Ecol. Lett. 9, 1228-1236.

Brose, U., Jonsson, T., Berlow, E.L., Warren, P., Banašek-Richter, C., Bersier, L.F., Blanchard, J.L., Brey, T., Carpenter, S.R., Cattin Blandenier, M.F., Cushing, L., Dawah, H.A., Dell, T., Edwards, F., Harper-Smith, S., Jacob, U., Ledger, M.E., Martinez, N.D., Memmott, J., Mintenbeck, K., Pinnegar, J.K., Rall, B.C., Rayner, T.S., Reuman, D.C., Ruess, L., Ulrich, W., Williams, R.J., Woodward, G., Cohen, J.E., 2006b. Consumerresource body-size relationships in natural food webs. Ecology 87, 2411-2417.

Caldarelli, G., Higgs, P.G., McKane, A.J., 1998. Modelling coevolution in multispecies communities. J. Theor. Biol. 193, 345.

Cattin, M.F., Bersier, L.F., Banašek-Richter, C., Baltensperger, R., Gabriel, J.P., 2004. Phylogenetic constraints and adaptation explain food-web structure. Nature 427, 835-839.

Cattin Blandenier, M.F., 2004. Food web ecology: models and application to conservation. $\mathrm{PhD}$ thesis, University of Neuchâtel, Switzerland.

Cohen, J.E., 1977. Food webs and the dimensionality of trophic niche space. Proc. Natl. Acad. Sci. USA 74, 4533-4536.

Cohen, J.E., 1978. Food Webs and Niche Space. Princeton University Press, Princeton, NJ.

Cohen, J.E., Newman, C.M., 1985. A stochastic theory of community food webs I. Models and aggregated data. Proc. R. Soc. Lond. B 224, 421-448.

Cohen, J.E., Palka, Z.J., 1990. A stochastic theory of community food webs. V. Intervality and triangulation in the trophicniche overlap graph. Am. Nat. 135, 435-463. 
Cohen, J.E., Briand, F., Newman, C.N., 1990. Community Food Webs: Data and Theory. Springer-Verlag, Berlin.

Cohen, J.E., Pimm, S.L., Yodzis, P., Saldana, J., 1993. Body sizes of animal predators and animal prey in food webs. J. Anim. Ecol. 62, 67-78.

Cohen, J.E., Jonsson, T., Carpenter, S.R., 2003. Ecological community description using the food web, species abundance, and body size. Proc. Natl. Acad. Sci. USA 100, 1781-1786.

Cohen, J.E., Jonsson, T., Muller, C.B., Godfray, H.C.J., Savage, V.M., 2005. Body sizes of hosts and parasitoids in individual feeding relationships. Proc. Natl. Acad. Sci. USA 102, 684-689.

Cousins, S.H., 1985. The trophic continuum in marine ecosystems: structure and equations for a predictive model. Can. J. Fish. Aquat. Sci. 213, 76-93.

Damuth, J., 1981. Population density and body size in mammals. Nature 290, 699-700.

Dawah, H.A., Hawkins, B.A., Claridge, M.F., 1995. Structure of the parasitoid communities of grass-feeding chalcid wasps. J. Anim. Ecol. 64, 708-720.

Deb, D., 1997. Trophic uncertainty vs parsimony in food web research. Oikos 78, 191-194.

Drake, J.A., 1990. Communities as assembled structures: do rules govern pattern? Trends Ecol. Evol. 5, 159-164.

Drossel, B., Higgs, P.G., McKane, A.J., 2001. The influence of predator-prey population dynamics on the long-term evolution of food web structure. J. Theor. Biol. 208, 91-107.

Finstad, A.G., Ugedal, O., Berg, O.K., 2006. Growing large in a low grade environment: size dependent foraging gain and niche shifts to cannibalism in Arctic char. Oikos 112, 73-82.

Goldwasser, L., Roughgarden, J., 1993. Construction and analysis of a large Caribbean food web. Ecology 74, 1216-1233.

Hall, S.J., Raffaelli, D., 1991. Food-web patterns: lessons from a species-rich web. J. Anim. Ecol. 60, 823-842.

Hansen, B., Bjornsen, P.K., Hansen, P.J., 1994. The size ratio between planktonic predators and their prey. Limnol. Oceanogr. 39, 395-403.

Harper-Smith, S., Berlow, E.L., Knapp, R.A., Williams, R.J., Martinez, N.D., 2005. Communicating ecology through food webs: visualizing and quantifying the effects of stocking alpine lakes with fish. In: De Ruiter, P., Moore, J.C., Wolters, V. (Eds.), Dynamic Food Webs: Multispecies Assemblages, Ecosystem Development, and Environmental Change. Elsevier/Academic Press, pp. 407-423.

Havens, K.E., 1992. Scale and structure in natural food webs. Science 257, 1107-1109.

Huxham, M., Beaney, S., Raffaelli, D., 1996. Do parasites reduce the chances of triangulation in a real food web? Oikos 76, 284-300.

Jonsson, T., Cohen, J.E., Carpenter, S.R., 2005. Food webs, body size, and species abundance in ecological community description. Adv. Ecol. Res. 36, 1-84.

Lawton, J.H., Warren, P.H., 1988. Static and dynamic explanations for patterns in food webs. Trends Ecol. Evol. 3, 242-245.

Legendre, P., Legendre, L., 1998. Numerical Ecology, second ed. Elsevier, Amsterdam.

Loeuille, N., Loreau, M., 2005. Evolutionary emergence of sizestructured food webs. Proc. Natl. Acad. Sci. USA 102, 57615766.

Losos, J.B., 1996. Phylogenetic perspectives on community ecology. Ecology 77, 1344-1354.

Martinez, N.D., 1991. Artifacts or attributes? Effects of resolution on the Little Rock Lake food web. Ecol. Monogr. 61, 367-392.

Martinez, N.D., Cushing, L.J., 2006. Additional model complexity reduces fit to complex food-web structure. In: Pascual, M., Dunne, J.A. (Eds.), Ecological Networks: Linking Structure and Dynamics. Oxford University Press, pp. 87-89.
Melián, C.J., 2005. On the Structure and Dynamics of Ecological Networks. PhD thesis, Universidad de Alcalá, Spain.

Memmott, J., Martinez, N.D., Cohen, J.E., 2000. Predators, parasitoids and pathogens: species richness, trophic generality and body sizes in a natural food web. J. Anim. Ecol. 69, 1-15.

Nagel, L., Schluter, D., 1998. Body size, natural selection, and speciation in sticklebacks. Evolution 52, 209-218.

Nee, S., Read, A.F., Greenwood, J.J.D., Harvey, P.H., 1991. The relationship between abundance and body size in British birds. Nature 351, 312-313.

Neubert, M.G., Blumenshine, S.C., Duplisea, D.E., Jonsson, T., Rashleigh, B., 2000. Body size and food web structure: testing the equiprobability assumption of the cascade model. Oecologia 123, 241-251.

Paine, R.T., 1988. Food web: road maps of interactions or grist for theoretical development? Ecology 69, 1648-1654.

Persson, L., 1987. The Effects of resource availability and distribution on size class interactions in perch Perca fluviatilis. Oikos 48, 148-160.

Pimm, S.L., 1982. Food Webs. Chapman, Hall, New York.

Pinnegar, J.K., Trenkel, V.M., Tidd, A.N., Dawson, W.A., DuBuit, M.H., 2003. Does diet in Celtic Sea fishes reflect prey availability? J. Fish Biol. 63 (Suppl. A), 197-212.

Polis, G.A., 1991. Complex trophic interactions in deserts: an empirical critique of food-web theory. Am. Nat. 138, 123-155.

Pratt, H.D., 2005. The Hawaiian Honeycreepers. Oxford University Press, Oxford, UK.

Price, P.W., 2003. Macroevolutionary Theory on Macroecological Patterns. Cambridge University Press, Cambridge, UK.

Richmond, J.Q., Jockusch, E.L., 2007. Body size evolution simultaneously creates and collapses species boundaries in a clade of scincid lizards. Proc. R. Soc. Lond. B 274m 17011708.

Rossberg, A.G., Matsuda, H., Amemiya, T., Itoh, K., 2005. An explanatory model for food-web structure and evolution. Ecol. Complex. 2, 312-321.

Rossberg, A.G., Matsuda, H., Amemiya, T., Itoh, K., 2006a. Some properties of the speciation model for food-web structuremechanisms for degree distributions and intervality. J. Theor. Biol. 238, 401-415.

Rossberg, A.G., Matsuda, H., Amemiya, T., Itoh, K., 2006b. Food webs: experts consuming families of experts. J. Theor. Biol. 241 (3), 552-563.

Rossberg, A.G., 2007. Part-whole relations between food webs and the validity of local food-web descriptions, Ecol. Complex, in press, doi:10.1016/ j.ecocom.2008.02.003.

Scharf, F.S., Juanes, F., Rountree, R.A., 2000. Predator size-prey size relationships of marine fish predators: interspecific variation and effects of ontogeny and body size on trophic-niche breadth. Mar. Ecol.-Prog. Ser. 208, 229-248.

Schluter, D., 2000. The Ecology of Adaptive Radiation. Oxford University Press, Oxford, UK.

Siemann, E., Tilman, D., Haarstad, J., 1996. Insect species diversity, abundance and body size relationships. Nature 380, 704-706.

Sokal, R.R., Rohlf, F.J., 1995. Biometry, third ed. Freeman, New York.

Sugihara, G., 1982. Niche hierarchy: structure assembly and organization in natural communities. $\mathrm{PhD}$ thesis, Princeton University, Princeton, USA.

Sugihara, G., 1984. Graph theory, homology and food webs. In: Levin, S.A. (Ed.). Proceedings of Symposia in Applied Mathematics, vol. 30. American Mathematical Society, Providence, Rhode Island, pp. 83-101. 
Sugihara, G., Bersier, L.-F., Southwood, T.R.E., Pimm, S.L., May, R.M., 1993. Predicted correspondence between species abundances and dendrograms of niche similarity. Proc. Natl. Acad. Sci. USA 100, 5246-5251.

Tripet, F., Perrin, N., 1994. Size-dependent predation by Dugesia lugubris (Turbellaria) on Physa acuta (Gastropoda)experiments and model. Funct. Ecol. 8, 458-463.

Ulrich, W., 1999. Species composition, coexistence and mortality factors in a carrion-exploiting community composed of necrophagous Diptera and their parasitoids (Hymenoptera). Pol. J. Ecol. 47, 49-72.

Ulrich, W., 2001. Hymenopteren in einem Kalkbuchenwald: Eine Modellgruppe zur Untersuchung von Tiergemeinschaften und ökologischen Raum-Zeit-Mustern. Schriftenreihe Forschungszentrum Waldökosysteme A 171, 1-249.

Vitt, L.J., Pianka, E.R., 2005. Deep history impacts present-day ecology and biodiversity. Proc. Natl. Acad. Sci. USA 102, 7877-7881.

Wahlstrom, E., Persson, L., Diehl, S., Bystrom, P., 2000. Sizedependent foraging efficiency, cannibalism and zooplankton community structure. Oecologia 123, 138-148.

Warren, P.H., 1989. Spatial and temporal variation in the structure of a freshwater food web. Oikos 55, 299-311.
Warren, P.H., Lawton, J.H., 1987. Invertebrate predator-prey body size relationship: an explanation for upper triangular food webs and patterns in food web structure? Oecologia 74, 231-235

Weitz, J.S., Levin, S.A., 2006. Size and scaling of predator-prey dynamics. Ecol. Lett. 9, 548-557.

Williams, R.J., Martinez, N.D., 2000. Simple rules yield complex food webs. Nature 404, 180-183.

Woodward, G., Speirs, D.C., Hildrew, A.G.H., 2005.

Quantification and resolution of a complex, size-structured food web. Adv. Ecol. Res. 36, 85-136.

Wrona, F.J., Prowse, T.D., Reist, J.D., Hobbie, J.E., Levesque, L.M.J., Vincent, W.F., 2006. Climate change effects on aquatic biota, ecosystem structure and function. AMBIO 35, 359-369.

Yodzis, P., 1998. Local trophodynamics and the interaction of marine mammals and fisheries in the Benguela ecosystem. J. Anim. Ecol. 67, 635-658.

Yoshida, K., 2002. Long survival of "living fossils" with low taxonomic diversities in an evolving food web. Paleobiology $28,464-473$.

Yoshida, K., 2003. Evolutionary dynamics of species diversity in an interaction web system. Ecol. Model. 163, 131-143. 